\title{
Effect of creatine malate supplementation on physical performance, body composition and selected hormone levels in spinters and long-distance runners
}

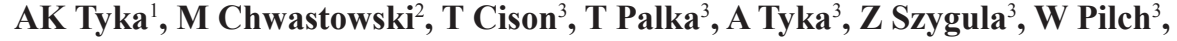 \\ M Strzala ${ }^{4}$, M Cepero $^{5}$ \\ ${ }^{1}$ Department of Recreation and Biological Regeneration, Faculty of Tourism and Leisure, University \\ of Physical Education, Cracow, Poland \\ ${ }^{2}$ Doctoral Studies, Faculty of Physical Education and Sports, University of Physical Education, Cracow, Poland \\ ${ }^{3}$ Department of Physiology and Biochemistry, Faculty of Physical Education and Sports, University \\ of Physical Education, Cracow, Poland \\ ${ }^{4}$ Department of the Theory and Methodology of Water Sports, Faculty of Physical Education and Sports, \\ University of Physical Education, Cracow, Poland \\ ${ }^{5}$ Faculty of Education, University of Granada, Granada, Spain
}

Received: April 16, 2014

Accepted after revision: September 26, 2014

\begin{abstract}
Purpose: The aim of the study was to determine whether creatine malate (CML) supplementation results in similar ergogenic effect in sprinters and long-distance runners. The other goal was to compare changes in body composition, physical performance and hormone levels after six-week training in athletes, divided into subgroups supplemented with creatine malate or taking placebo. Results: Six-week supplementation combined with physical training induced different effects in athletes. Significantly higher increases in relative and absolute peak power and total work $(p<$ 0.05 ) were found in sprinters compared to other groups. Except for growth hormone, post-exercise venous blood serum hormone levels exhibited no statistically significant differences in athletes. After CML loading period, a significant increase in growth hormone was found in the group of sprinters. Conclusions: A significant ergogenic effect was found in sprinters, which was reflected by the increase in anaerobic exercise indices and morphological indices and elevated growth hormone level, after graded exercise testing. The significant increase in the distance covered during graded test was only observed in supplemented long-distance runners, whereas no significant changes in maximal oxygen uptake, relative peak power and relative total work were noticed. This could be caused by later anaerobic threshold appearance in exercise test to exhaustion.
\end{abstract}

Keywords: long-distance runners, sprinters, creatine malate supplementation, body composition, maximal oxygen uptake, peak power output, growth hormone, cortisol, testosterone

The effect of creatine on physical performance development is a subject of interest among many researchers. Since its discovery in 1832 by Chevreul, the effect of creatine on the human body has been investigated in numerous laboratories all over the world. The welldocumented properties of creatine include its biosynthesis and distribution in human body $(19,39)$, its role in energy conversion in skeletal muscles and delayed fatigue $(18,20,40)$, pattern and the effect of creatine intake on ability to perform physical exercise $(2,7,12,13)$.

Corresponding author: Anna Tyka, $\mathrm{PhD}$

Department of Recreation and Biological Regeneration, University School of Physical Education,

Al. Jana Pawla II 78, 31-571 Cracow, Poland

Phone: +48 126831034; Fax: +48 126831401; E-mail: anna.tyka@awf.krakow.pl 
The strategy of creatine monohydrate supplementation in athletes has also attracted a great deal of scientific attention $(1,4-6,8,9,11,23,25,27,28,31,32,38)$. Studies have been carried out in elite athletes, including swimmers, sprinters, American football players as well as older non-athletes.

On the other hand, if consumed in smaller doses, creatine malate (CML) has been reported to have an ergogenic effect similar to creatine monohydrate $(21,34)$. As one of the carboxylic acids, it easily permeates through mitochondria and transports products of glucose breakdown. It plays an essential role in energy metabolism that occurs in muscle cells, which contributes to facilitating energy provision during anaerobic processes (30).

Considering the above, the authors decided to use this preparation in supplementation of athletes in the study. The effect of small doses of CML on ability to physical exercise and hormonal response has not been sufficiently investigated to date and needs further research since only few studies included creatine malate as a supplement in speed-strength and endurance disciplines. It is essential to know how creatine malate affects sprinters and longdistance runners who have completely different muscle fibres composition.

The creatine compounds have been known to affect hormonal control, particularly in the area of fluctuation of endogenous testosterone, whereas physical exercise combined with supplementation of these compounds modifies metabolic body response even further (29). This is reflected by the elevated blood serum levels of certain hormones, such as human growth hormone (hGH), testosterone $(\mathrm{T})$ and cortisol $(\mathrm{C})$, which occurs simultaneously with changes in skeletal muscles (increased mass, tension and power). Growth hormone (hGH), which releases fatty acids necessary for muscular work, contributes to improved muscle mass. The increase in its concentration in venous blood serum during physical work was observed by Matsuse et al. (26) and by Madarame et al. (24). These authors also emphasized high contribution of androgens to increase muscle mass caused by training (17, 36-38).

The aim of the study was to provide the answers to the questions whether:

- supplementation with small CML doses in sprinters (SCML) and long-distance runners (LCML) results in similar ergogenic effect?

- changes in morphological body composition, physical performance and hormonal status after six-week supplementation period with CML and athletic training in SCML and LCML groups are similar to those observed in men who run the same training regime but took placebo (Spl and Lpl)?

\section{Materials and Methods}

The study covered professional male athletes (runners) aged 19 to 30 years: 18 sprinters (S), specialized in 100 to $400 \mathrm{~m}$, and 20 long-distance runners (L), running distances from 10 to $42 \mathrm{~km}$. Their sport experience varied between 6 to 14 years and they did not consume the creatine supplements for at least a year before the study. The athletes, both $\mathrm{S}$ and $\mathrm{L}$, were randomly divided into 2 subgroups with, respectively, $n=9$ and $n=10$. The training programme was similar for each pair of athletes: one from creatine and the other from a placebo group. The supplemented sprinters (SCML) and long-distance runners (LCML) took oral doses of creatine malate $(\mathrm{CML})$, whereas other groups ( $\mathrm{Spl}$ and $\mathrm{Lpl}$ ) were administered placebo.

The sprinters compared to the long-distance runners were characterized by having higher body mass (BM), lean body mass (LBM), body mass index (BMI), peak power (PP) and relative peak power (RPP) $(p<0.05)$. However there were no significant differences in 
morphological indices between placebo and creatine malate groups in any of the subgroups ( $\mathrm{S}$ and $\mathrm{L}$ ). Higher level of $\mathrm{VO}_{2} \max$ was observed in long-distance runners (L), which coincided with greater trial distance (D) and better aerobic capacity in the graded exercise test $(p<0.05)$.

The research project was funded by NCN (the National Science Centre) and the experiment was approved by the Research Bioethics Committee at the Regional Medical Chamber in Cracow, Poland (No. 76 KBL/OIL/2008). The study was carried out during an initial mesocycle and the basic preparatory period. Nutrition patterns of the athletes studied were analysed, using the data from 7 consecutive days, which were collected by means of recording daily nutritional intake in a food diary by the athletes, using the Picture book of products and foods (35). In order to evaluate diet calorific content and the content of proteins, fat and carbohydrates in food, tables of nutritional values in foods (22) were used. The content of nutrients was evaluated by means of Wikt 3.0 software (Net-komputer, 2002) and was determined as a per cent energy share of proteins, fat and carbohydrates in daily energy intake. The mean calorific content in the daily food was $2893 \pm 202.01 \mathrm{kcal}$. Based on basic nutrients intake evaluation, the authors demonstrated that the intake of proteins, fat and carbohydrates was $16 \%, 49 \%$ and $35 \%$ of the energy intake in the diet, respectively.

The programme of the experiment encompassed the preliminary examinations, the aim of which was to get the men acquainted with the test procedure as well as to identify the relative exercise test loads, and the main examinations - divided into initial (I) and final (II), after a 6-week training and supplementation period. Then, men from the SCML and LCML groups were supplemented with CML capsules (TCM, Olimp Labs, Poland) that were administered orally, every day, after breakfast for 6 weeks. The preparation was dosed with $250 \mathrm{ml}$ of still, room temperature water. The dose of $0.07 \mathrm{~g} \times \mathrm{kg}^{-1} \mathrm{LBM}$ was used, which corresponded to $5 \mathrm{~g}$ of the preparation for a person with $\mathrm{LBM}$ of $70 \mathrm{~kg}$ (5). A similar procedure of taking placebo capsules, which looked exactly the same as CML capsules but contained potato starch, were employed for athletes from the Spl and Lpl groups. Double-blind placebo design was used and the subjects were not aware of the capsules' content. All of them were informed that the participants would take a permissible sports supplement for the 6-week period. During this period, pairs of athletes (CML and pl) trained according to the same, but individual for each pair, workout. The runners agreed not to take other supplements during experiment, which was controlled by their coaches.

The main examinations, both I and II, were focused on morphological body composition measurements and physiological indices recorded before, during and after completion of the exercise tests. During the first day the participants performed anaerobic tests. On the following day, the graded test. After the six-week CML supplementation period, the athletes started the second part of the main examinations. All measurements were taken between 9:00 am and 11:00 am for two consecutive weekdays. The examinations were carried out in a climatic chamber with ambient temperature of $21^{\circ} \mathrm{C} \pm 0.5{ }^{\circ} \mathrm{C}$, relative humidity of $50 \% \pm 5 \%$ and air circulation below $0.5 \mathrm{~m} \mathrm{~s}^{-1}$. The ambient temperature and relative air humidity were measured by means of MRV-A Ellab electrical thermometer and thermo-hygrometer with accuracy of $\pm 0.5{ }^{\circ} \mathrm{C}$ and $\pm 3 \%$, respectively. Measurements of body mass (BM) were taken with $\pm 1 \mathrm{~g}$ accuracy by means of F1505-DZA Sartorius while those of body height (BH) by means of Martin's anthropometer. Per cent fat (PF), lean body mass (LBM) and body mass index (BMI) were measured with densitometer Lunar Prodigy Primo Full, enCORE with body composition option, manufactured by GE Healthcare Technologies. 


\section{Anaerobic and aerobic tests}

Wingate test (3) was carried out using Corival Ergometer (Lode BV). The test was preceded with a 5-minute warm-up (WU) at the intensity of $50 \% \mathrm{VO}_{2} \max$ (established in preliminary examinations) and pedalling frequency of $70 \mathrm{rpm}$, with three 5 -second maximum acceleration bouts at the end of the 2nd, 4 th and 5 th minute. The authors determined the optimum load on the ergometer platters in the preliminary study for sprinters - 9\% BM and long-distance runners $-8.3 \%$ BM. Relative peak power (RPP), absolute peak power (PP) and total work (RTW and TW) were measured during a 30-second exercise test. The warm-up was carried out on a VIAAsprint 150P Bicycle Ergometer.

The graded exercise test was performed during the second day of the examination, using a HP Cosmos Saturn treadmill. After a 3-minute warm-up (running with the speed of 2.3 $\mathrm{m} \cdot \mathrm{s}^{-1}$ ) the speed was incremented every three minutes with $0.5 \mathrm{~m} \cdot \mathrm{s}^{-1}$. During the exercise, minute oxygen uptake $\left(\mathrm{VO}_{2}\right)$, heart rate $(\mathrm{HR})$ and blood pressure $(\mathrm{BP})$ were measured using OxyconPro apparatus (CareFusion Healthcare $\mathrm{GmbH}$ ). The trial distance (D) was also recorded.

Hematocrit (Hct) and hemoglobin concentration $(\mathrm{Hb})$ were measured in the venous blood taken from the antecubital vascular access whereas the immunoenzymatic test was used for measurement of blood serum levels of testosterone (T), cortisol (C) and growth hormone $(\mathrm{hGH})$. Blood with volume of $10 \mathrm{ml}$ was sampled to DB test-tubes (Vacutainer, USA) containing coagulation activator. Blood was prepared in a MPW 350 centrifuge (MPW Med. Instruments). Changes in blood plasma volume $(\% \Delta \mathrm{PV})$ were evaluated using Dill and Costill formula (10) modified by Harrison et al. (16). Blood hemoglobin ( $\mathrm{Hb}$ ) and glucose levels were measured in Sysmex XE 2100 device, whereas hematocrit (Hct) was evaluated using MPW 251 centrifuge (MPW Med. Instruments). Determination of the concentrations was carried out using the E-Liza Mat 3000 microplate reader manufactured by DRG Instruments Gmbh and the following tests were conducted three times for each blood sample (the average results were presented): DRG Testosterone ELISA EIA-1559 for testosterone (T), DRG Cortisol ELISA EIA-1887 for cortisol (C) and DRG hGH ELISA EIA-1787 for growth hormone (hGH) by DRG Instruments Gmbh.

\section{Statistical analysis}

The numerical data were processed using Statistica 9.0 for Windows (StatSoft). The following descriptive statistics were calculated: mean $(\bar{x})$, standard deviation (SD) and differences between measurement I; II $(\Delta)$. Wilcoxon test was used for dependent trials and MannWhitney U test for intergroup comparisons. Taking the distribution of the dependent variables (Shapiro-Wilk test) into consideration dependent Student $t$-tests were used. The differences between after and before results in both supplemented and placebo groups were analysed by factorial (two-way, group $\times$ treatment) ANOVA with repeated measures. The probability level for significance was set at $p<0.05$.

\section{Results}

The six-week supplementation with CML combined with physical training induced different effects in the athletes studied (Table I A, B). Significantly higher increases in relative and absolute peak power $(\Delta \mathrm{RPP}$ and $\Delta \mathrm{PP})$ and total work $(\Delta \mathrm{RTW}$ and $\Delta \mathrm{TW})(p<0.05)$ were found in sprinters (SCML) compared to other groups of runners (Spl, LCML and Lpl). No similar (to SCML group) ergogenic effect was observed in the group of LCML. Furthermore, 
no significant changes in maximum oxygen uptake $\left(\mathrm{VO}_{2} \mathrm{max}\right)$ were found in the tests after supplementation (Table I A, B). A significant reduction in relative $\mathrm{VO}_{2}$ max results was found only in the group of SCML, which coincided with the significant increase in the peak power (PP) and total work (TW), which indicates a deterioration of aerobic processes and improve anaerobic ones. Supplementation with CML in the L group caused a significant increase in the distance (D) during the graded exercise test $(p<0.05)$ in the test II. The groups of sprinters (SCML, Spl) and long-distance runners (LCML, Lpl) differed significantly in aerobic capacity level $\left(\mathrm{VO}_{2} \max \right)$ and anaerobic capacity indices (PP and TW) $(p<0.05)$. In the anaerobic test, sprinters generated significantly higher peak power (PP and RPP) and performed greater work (TW and RTW) compared to long-distance runners $(p<0.05)$. None of mentioned indices in the test I (Table I) in the supplemented and placebo groups, either in sprinters or in long-distance runners, differed statistically among the subgroups ( $\mathrm{S}$ and L) (Table I).

Table I. Morphological indices in first test in sprinters and long-distance runners in creatine malate (SCML and LCML) and placebo groups ( $\mathrm{Spl}$ and $\mathrm{Lpl}$ ) and the changes between after/before supplementation results $(\Delta)$

A) Sprinters (S)

\begin{tabular}{|l|c|c|c|c|}
\hline Index & $\begin{array}{c}\text { SCML } \\
(\mathbf{x} \pm \mathbf{S D})\end{array}$ & $\begin{array}{c}\boldsymbol{\Delta} \\
(\mathbf{x})\end{array}$ & $\begin{array}{c}\text { Spl } \\
(\mathbf{x} \pm \mathbf{S D})\end{array}$ & $\begin{array}{c}\Delta \\
(\mathbf{x})\end{array}$ \\
\hline $\mathrm{BM}(\mathrm{kg})$ & $82.39 \pm 3.19$ & $2.15^{* \#}$ & $80.60 \pm 3.65$ & $0.75^{\#}$ \\
\hline PF $(\%)$ & $9.29 \pm 0.91$ & $1.01^{*}$ & $8.71 \pm 0.78$ & $1.08^{*}$ \\
\hline $\mathrm{LBM}(\mathrm{kg})$ & $74.50 \pm 4.76$ & $1.29^{* \#}$ & $73.63 \pm 5.43$ & $0.09^{\#}$ \\
\hline $\mathrm{BMI}\left({\left.\mathrm{kg} \times \mathrm{m}^{-2}\right)}^{25.00 \pm 1.77}\right.$ & $0.69^{*}$ & $26.00 \pm 1.87$ & 0.24 \\
\hline
\end{tabular}

B) Long-distance runners (L)

\begin{tabular}{|l|c|c|c|c|}
\hline Index & $\begin{array}{c}\text { LCML } \\
(\mathbf{x} \pm \text { SD) }\end{array}$ & $\begin{array}{c}\Delta \\
(\mathbf{x})\end{array}$ & $\begin{array}{c}\text { Lpl } \\
(\mathbf{x} \pm \text { SD) }\end{array}$ & $\begin{array}{c}\Delta \\
(\mathbf{x})\end{array}$ \\
\hline BM $(\mathrm{kg})$ & $65.51 \pm 3.54$ & 0.54 & $65.25 \pm 3.64$ & 0.85 \\
\hline PF $(\%)$ & $6.72 \pm 2.21$ & 0.53 & $6.72 \pm 1.81$ & 1.01 \\
\hline LBM $(\mathrm{kg})$ & $61.17 \pm 3.81$ & 0.25 & $60.26 \pm 4.74$ & 0.13 \\
\hline BMI $\left({\left.\mathrm{kg} \times \mathrm{m}^{-2}\right)}^{2}\right.$ & $21.4 \pm 1.18$ & 0.17 & $20.8 \pm 2.19$ & 0.26 \\
\hline
\end{tabular}

Significant differences at the level of $p<0.05$ (*after - before, $\left.{ }^{*} \Delta \mathrm{SCML}-\Delta \mathrm{Spl}, \Delta \mathrm{LCML}-\Delta \mathrm{Lpl}\right)$

Morphological body composition indices (BM, PF, LBM and BMI) were higher by 17 to $20 \%$ in sprinters (S) compared to long-distance runners (L) (Table II A, B). A significant increase in these indices was found in the group of sprinters (SCML) $(p<0.05)$, whereas (from the groups that took placebo) only an increase in percentage fat was observed in the group of Spl $(p<0.05)$. These changes were not found in the L group (Table II A).

Post-exercise venous blood serum hormone levels exhibited no statistically significant differences in the athletes studied, except for hGH (Table III A, B). After the period of CML loading, a significant increase $(p<0.05)$ in growth hormone $(\Delta \mathrm{hGH})$ was found only in the group of sprinters (SCML). 
Table II. Physiological indices and trial distance in the first test in sprinters (SCML and Spl) and long-distance runners (LCML and $\mathrm{Lpl}$ ) and the changes between measurements before and after 6-week-supplementation period $(\Delta)$

Sprinters (S)

\begin{tabular}{|c|c|c|c|c|}
\hline Index & $\begin{array}{c}\text { SCML } \\
(x \pm \text { SD })\end{array}$ & $\begin{array}{c}\Delta \\
(\mathbf{x})\end{array}$ & $\begin{array}{c}\text { Spl } \\
(x \pm \text { SD })\end{array}$ & $\begin{array}{c}\Delta \\
(\mathbf{x})\end{array}$ \\
\hline $\mathrm{VO}_{2} \max \left(1 \times \min ^{-1}\right)$ & $4.81 \pm 1.01$ & 0.08 & $4.25 \pm 0.45$ & -0.01 \\
\hline $\mathrm{VO}_{2} \max \left(\mathrm{ml} \times \mathrm{kg}^{1} \times \min ^{-1}\right)$ & $57.20 \pm 5.81$ & $-2.52 *$ & $55.60 \pm 4.65$ & -0.61 \\
\hline $\mathrm{D}(\mathrm{m})$ & $3436 \pm 399.11$ & -140 & $3878 \pm 364.60$ & -164 \\
\hline $\mathrm{PP}(\mathrm{W})$ & $1098 \pm 32.18$ & $101^{* \#}$ & $1090 \pm 19.30$ & $10^{\#}$ \\
\hline $\operatorname{RPP}\left(\mathrm{W} \times \mathrm{kg}^{-1}\right)$ & $13.11 \pm 1.03$ & $1.05^{* \#}$ & $13.53 \pm 0.98$ & $0.05^{\#}$ \\
\hline $\mathrm{TW}(\mathrm{kJ})$ & $23.40 \pm 2.95$ & $1.91 * \#$ & $22.82 \pm 2.64$ & $0.68^{\#}$ \\
\hline $\mathrm{TW}\left(\mathrm{J} \times \mathrm{kg}^{-!}\right)$ & $285.2 \pm 14.30$ & $14.8^{* \#}$ & $284 \pm 15.82$ & $5^{\#}$ \\
\hline
\end{tabular}

B) Long-distance runners (L)

\begin{tabular}{|l|c|c|c|c|}
\hline Index & $\begin{array}{c}\text { LCML } \\
(\mathbf{x} \pm \mathbf{S D})\end{array}$ & $\begin{array}{c}\boldsymbol{\Delta} \\
(\mathbf{x})\end{array}$ & $\begin{array}{c}\text { Lpl } \\
(\mathbf{x} \pm \mathbf{S D})\end{array}$ & $\begin{array}{c}\Delta \\
(\mathbf{x})\end{array}$ \\
\hline $\mathrm{VO}_{2} \mathrm{max}\left(1 \times \mathrm{min}^{-1}\right)$ & $4.61 \pm 0.66$ & -0.03 & $4.46 \pm 0.60$ & 0.02 \\
\hline $\mathrm{VO}_{2} \mathrm{max}\left(\mathrm{ml} \times \mathrm{kg}^{-1} \times \mathrm{min}^{-1}\right)$ & $70.10 \pm 8.54$ & -0.89 & $69.20 \pm 7.18$ & -1.99 \\
\hline $\mathrm{D}(\mathrm{m})$ & $5099 \pm 424.60$ & $645^{*}$ & $4954 \pm 468.70$ & 44.0 \\
\hline $\mathrm{PP}(\mathrm{W})$ & $732.8 \pm 24.69$ & 16.0 & $745 \pm 25.82$ & 4.0 \\
\hline $\mathrm{RPP}\left(\mathrm{W} \times \mathrm{kg}^{-1}\right)$ & $11.19 \pm 1.07$ & 0.14 & $11.32 \pm 0.94$ & 0.22 \\
\hline $\mathrm{TW}(\mathrm{kJ})$ & $17.54 \pm 1.69$ & 0.36 & $18.10 \pm 3.70$ & 0.02 \\
\hline $\mathrm{TW}\left(\mathrm{J} \times \mathrm{kg}^{-!}\right)$ & $267.5 \pm 12.20$ & 5.0 & $274.4 \pm 15.10$ & 2.0 \\
\hline
\end{tabular}

Significant differences at the level of $p<0.05$ (*after - before, ${ }^{*} \Delta \mathrm{SCML}-\Delta \mathrm{Spl}, \Delta \mathrm{LCML}-\Delta \mathrm{Lpl}$ )

Table III. Hormone levels in the first test after graded exercise test in sprinters (SCML and Spl) and long-distance runners (LCML and Lpl) and the changes after 6-week-supplementation period $(\Delta)$

A) Sprinters (S)

\begin{tabular}{|l|c|c|c|c|}
\hline Index & $\begin{array}{c}\text { SCML } \\
(\mathbf{x} \pm \mathbf{S D})\end{array}$ & $\begin{array}{c}\boldsymbol{\Delta} \\
(\mathbf{x})\end{array}$ & $\begin{array}{c}\text { Spl } \\
(\mathbf{x} \pm \text { SD })\end{array}$ & $\begin{array}{c}\Delta \\
(\mathbf{x})\end{array}$ \\
\hline Testosterone $[\mathrm{T}]\left({\left.\mathrm{ng} \times \mathrm{ml}^{-1}\right)}\right.$ & $0.92 \pm 0.42$ & 0.06 & $0.17 \pm 1.46$ & -0.01 \\
\hline Cortisol $[\mathrm{C}]\left(\mathrm{ng} \times \mathrm{ml}^{-1}\right)$ & $13.29 \pm 4.92$ & -2.13 & $14.20 . \pm 3.60$ & -1.67 \\
\hline Growth hormone $[\mathrm{hGH}]\left(\mathrm{ng} \times \mathrm{ml}^{-1}\right)$ & $12.50 \pm 3.18$ & $5.69^{* \#}$ & $13.98 \pm 3.80$ & $0.95^{\#}$ \\
\hline
\end{tabular}

B) Long-distance runners (L)

\begin{tabular}{|l|c|c|c|c|}
\hline Index & $\begin{array}{c}\text { LCML } \\
(\mathbf{x} \pm \mathbf{S D})\end{array}$ & $\begin{array}{c}\boldsymbol{L} \\
\mathbf{( x )}\end{array}$ & $\begin{array}{c}\text { Lpl } \\
(\mathbf{x} \pm \text { SD })\end{array}$ & $\begin{array}{c}\Delta \\
\mathbf{( x )}\end{array}$ \\
\hline Testosterone $[\mathrm{T}]\left({\left.\mathrm{ng} \times \mathrm{ml}^{-1}\right)}^{1.38 \pm 0.38}\right.$ & -0.61 & $0.98 \pm 1.69$ & -0.65 \\
\hline Cortisol [C] $\left(\mathrm{ng} \times \mathrm{ml}^{-1}\right)$ & $18.05 \pm 2.28$ & 1.25 & $17.33 \pm 4.01$ & 1.02 \\
\hline Growth hormone $[\mathrm{hGH}]\left(\mathrm{ng} \times \mathrm{ml}^{-1}\right)$ & $1.78 \pm 3.13$ & 0.36 & $2.41 \pm 4.56$ & 0.15 \\
\hline
\end{tabular}

Significant differences at the level of $p<0.05$ (*after - before, $\left.{ }^{*} \Delta \mathrm{SCML}-\Delta \mathrm{Spl}, \Delta \mathrm{LCML}-\Delta \mathrm{Lpl}\right)$ 


\section{Discussion}

Following the introduction of newer forms of creatine into the marketplace and despite the great knowledge of creatine monohydrate $(\mathrm{CM})$ supplementation, further research on efficacy, safety and regulatory status of new forms should be conducted. The views of researchers on the effects of $\mathrm{CM}$ preparations on physical exercise with different intensity and the processes of muscular fatigue continue to arouse controversy $(2,7,12-14)$. In a laboratory study where double blind placebo protocol was used and male subjects were taking $5 \mathrm{~g}$ of creatine 4 times a day for 5 consecutive days, the amount of work performed with one leg during exercise with maximal intensity was increased (6). This was also observed in the athletes, who took CM that it contributed to delayed fatigue and as a consequence the increase of anaerobic work. Creatine monohydrate supplementation increased the work done during $30 \mathrm{~s}$ anaerobic isokinetic exercise by $5-7 \%(15)$.

There are not many reports on creatine malate supplementation, however a study carried out among judokas showed that supplementation with CML did not cause the expected ergogenic effect and no changes in body constitution were noticed (34). It is worth emphasizing that the study was carried out with a non-representative sample of athletes.

For this study the authors chose the most commonly used creatine malate (CML) dose, which was of $0.07 \mathrm{~g} \times \mathrm{kg}^{-1} \mathrm{LBM}(5 \mathrm{~g} / 70 \mathrm{~kg} \mathrm{LBM})(5,34)$. This was explained by the fact that daily pool of endogenous creatine amount should be $2 \mathrm{~g}$ for a person with LBM $-70 \mathrm{~kg}$ and the body consumes $2 \mathrm{~g}$ daily, which is in half regained through re-synthesis in the liver, whereas the remaining $1 \mathrm{~g}$ should be delivered with food (29).

Our study seems to provide useful information, especially due to the substantial differences in body composition, with particular focus on the structure of skeletal muscles. As well as the level of aerobic and anaerobic capacity and hormonal response to physical stimuli. These body properties are likely to substantially contribute to reactivity of the supplements used. Different effect of CML supplementation was found in groups of sprinters and long-distance runners. However the beneficial ergogenic effect was only observed in sprinters. It resulted in significant increases in anaerobic power (RPP and PP), total work (RTW and TW) in Wingate test and changes in body composition (BM, LBM, BMI). The 6-week CML supplementation and sprinters' training regime have contributed to increased phosphagen pool in large locomotor muscles, which improved the anaerobic capacity due to delayed fatigue. Ergogenic supplementation effect in sprinters also resulted in a significant increase in growth hormone $(\Delta \mathrm{hGH})$ compared to other groups. After 6 weeks of supplementation the increase in hGH $(\Delta)$ after exercise in SCML group was significantly higher than in the SPl, indicating that supplementation of CML intensified the secretion of the hormone, thus increasing the ergogenic effect. It is known that growth hormone concentration increases during physical effort, which causes the release of free fatty acids (FFA) that are necessary to perform the work and hGH also contributes to increased muscle mass $(24,26)$. This result was also observed in our study. Further detailed explanation of the differences in body response to creatine malate supplementation in sprinters and long-distance runners requires invasive tests.

It is known that the proportions of muscle fibres [type I (ST) and type II (FT)] and the amount of muscle phosphagen (ATP-CP) in athletes differ depending if it is speed-strength or endurance sports discipline (33). Certain study results (40) have demonstrated that creatine compounds supplementation is the most effective in people with the lowest availability of muscular creatine. Based on the above, the authors expected greater ergogenic effect of CML supplementation in long-distance runners (with advantage of type I fibres and lower 
phosphagen level) than in sprinters. However our study did not confirm those predictions. After the 6-week CML supplementation period, the trial distance covered during the graded exercise test in LCML was significantly longer than in a group that took placebo (Lpl).

\section{Conclusions}

The effect of a six-week creatine malate supplementation varied in sprinters and long-distance runners. The significant ergogenic effect was only found in sprinters (SCML), which was reflected by the increase in anaerobic exercise indices (PP, RPP, TW and RTW) and morphological indices (BM, PF, LBM and BMI) and the elevated growth hormone level in blood serum, measured after graded exercise test. Perhaps it is due to greater reactivity of supplement in sprinters than in long-distance runners. The significant rise in the running distance (D) observed in the supplemented long-distance runners (LCML) did not coincide with significant changes in maximal oxygen uptake, relative peak anaerobic power and relative total work, which might suggest positive effect of supplementation on aerobic endurance development. However the mechanism of these changes remains unclear and needs further research.

\section{REFERENCES}

1. Ahmun RP, Tong RJ, Grimshaw PN: The effects of acute creatine supplementation in multiple sprint cycling and running performance in rugby players. J. Strength Cond. Res. 19(1), 92-97 (2005)

2. Balsom PD, Harridge SDR, Söderlund K, Sjödin B, Ekblom B: Creatine supplementation per se does not enhance endurance exercise performance. Acta Physiol. Scand. 149, 521-523 (1993)

3. Bar-Or O: The Wingate anaerobic test: An update on methodology, reliability, and validity. Sports Med. 4, 381-394 (1987)

4. Bemben MG, Bemben DA, Loftiss DD, Knehans AW: Creatine supplementation during resistance training in college football athletes. Med. Sci. Sports Exerc. 33(10), 1667-1673 (2001)

5. Bemben MG, Lamont HS: Creatine supplementation and exercise performance. Sports Med. 35(2), 107-125 (2005)

6. Bemben MG, Witten MS, Carter JM, Eliot KA, Knehans AW, Bemben DA: The effect of supplementation with creatine and protein on muscle strength following a traditional resistance training program in middle-aged and older men. J. Nutr. Health Aging 14(2), 155-159 (2010)

7. Birch R, Noble D, Greenhaff PL: The influence of dietary creatine suplementation on performance during repeated bouts of maximal isokinetic cycling in men. Eur. J. Appl. Physiol. Occup. Physiol. 69(3), 268-276 (1994)

8. Candow DG, Chilibeck PD, Chad KE, Chrusch MJ, Davison KS, Burke DG: Effect of ceasing creatine supplementation while maintaning resistance training in older men. J. Aging Phys. Activ. 12, 219-231 (2004)

9. Chwalbińska-Moneta J: Effect of creatine supplementation on aerobic performance and anaerobic capacity in elite rowers in the course of endurance training. Int. J. Nutr. Exerc. Metab. 13(2), 173-183 (2003)

10. Dill DB, Costill DL: Calculation of percentage changes in volumes of blood, plasma, and red cells in dehydration. J. Appl. Physiol. 37, 247-248 (1974)

11. Fukuda DH, Smith AE, Kendall KL, Dwyer TR, Kersick CM, Beck TW, Cramer JT, Stout JR: The effect of creatine loading and gender on anaerobic running capacity. J. Strength Cond. Res. 24(7), 1826-1833 (2010)

12. Greenhaff PL: The influence of oral creatine supplementation on muscle torque during repeated bouts of maximal voluntary exercise in men. Clin. Sci. 84, 565-571 (1993)

13. Greenhaff PL, Bodin K, Soderlund K, Hultman E: Effect of oral creatine supplementation on skeletal muscle PCr resynthesis. Am. J. Physiol. 266, 725-730 (1994)

14. Greenhaff PL: Creatine: its role in physical performance and fatigue and its application as a sports food supplement. Int. J. Sport Nutr. 5 (suppl), 100 (1995) 
15. Harris RC, Soderlund K, Hultman E: Elevation of creatine in resting and exercised muscle of normal subjects by creatine supplementation. Clin. Sci. 83(3), 367-374 (1992)

16. Harrison NH, Graveney MJ, Cochrane LA: Some sources of error in the calculation of relative change in plasma volume. Eur. J. Appl. Physiol. Occup. Physiol. 50, 13-211 (1982)

17. Hiruntrakul A, Nanagara R, Emasithi A, Borer KT: Effect of endurance exercise on resting testosterone levels in sedentary subjects. Centr. Eur. J. Pub. Health. 18(3), 169-172 (2010)

18. Hultman E, Greenhaff PL, Ren JM, Soderlund K: Energy metabolism and fatigue during intense muscle contraction. Biochem. Soc. Tran. 19, 347-353 (1991)

19. Hunter A: The physiology of creatine and creatinine. Physiol. Rev. 2, 586-599 (1922)

20. Katz A, Sahlin K, Henriksson J: Muscle ATP turnover rate during isometric contraction in humans. J. Appl. Physiol. 60, 1839-1842 (1986)

21. Kreider RB, Melton C, Rasmusen CJ, Greenwood M, Lancaster S, Cantler EC, Milnor P, Almada AL: Long-term creatine supplementation does not significantly affect clinical markers of healt in athletes. Mol. Cell. Biochem. 244, 95-104 (2003)

22. Kunachowicz H, Nadolna I, Przygoda B, Iwanow K (2008): Tables of nutritional values in foods. PZWL, Warszawa

23. Kurosawa Y, Hamaoka T, Katsumura T, Kuwamori M, Kimura N, Sako T, Chance B: Creatine supplementation enhances anaerobic ATP synthesis during a single $10 \mathrm{sec}$ maximal handgrip exercise. Mol. Cell. Biochem. 244, 105-112 (2003)

24. Madarame H, Sasaki K, Ishii N: Endocrine responses to upper- and lower-limb resistance exercices with blood flow restriction. Acta Physiol. Hung. 97(2), 192-200 (2010)

25. Maganaris CN, Maughan RJ: Creatine supplementation enhances maximum voluntary isometric force and endurance capacity. Acta Physiol. Scand. 163, 279-287 (1998)

26. Matsuse H, Nago T, Takano Y, Shiba N: Plasma growth hormone is elevated immediately after resistance exercise with eletrical stimulation and voluntary muscle contraction. Tohoku J Exp. Med. 222(1), 69-75 (2010)

27. Maughan RJ: Creatine supplementation and exercise performance. Int. J. Sport Nut. 5, 94-101 (1995)

28. McMorris T, Harris RC, Swain J, Corbett, Collard K, Dyson RJ, Dye L, Hodgson C, Draper N: Effect of creatine supplementation and sleep deprivation, with mild exercise, on cognitive and psychomotor performance, mood state and plasma concentrations of catecholamines and cortisol. Psychopharmacol. 185, 93-103 (2006)

29. Mesa JLM, Ruiz JR, Gonzalez-Gross MM, Gutierrez Sainz A, Castillo Garzon MJ: Oral creatine supplementation and skeletal muscle metabolism in physical exercise. Sports Med. 32(14), 903-944 (2002)

30. Murray RK, Granner DK, Rodwell VW (1998): Harper's Biochemistry. PZWL, Warszawa

31. Preen D, Dawson B, Goodman C, Lawrence S, Beilby J, Ching S: Effect of creatine loading on long-term sprint exercise performance and metabolism. Med. Sci. Sports Exerc. 33(5), 814-821 (2001)

32. Rossouw F, Kruger PE, Rossouw J: The effect of creatine monohydrate loading on maximal intermittent exercise and sport-specific strength in well trained power-lifters. Nutr. Res. 20(4), 505-514 (2000)

33. Saltin B, Gollnick PD (2011): Skeletal muscle adaptability: significance for metabolism and performance. In: Comprehensive Physiology. Am. Physiol. Soc. DOI:10.1002/cphy.cp100119

34. Sterkowicz S, Tyka AK, Chwastowski M, Sterkowicz-Przybycień K, Tyka A, Kłys A: The effect of training and creatine malate supplementation during preparation period on physical capacity and special fitness in judo contestants. J. Int. Soc. Sports Nutr. 9, 41 DOI:10.1186/1550-2783-9-41 (2012)

35. Szponar L, Wolnicka K, Rychlik E (2000): Picture book of products and foods. Wyd. Inst. Żyw. i Żywienia, Warszawa

36. Thomas NE, Leyshon A, Hughes MG, Davies B, Graham M, Baker JS: The effect of anaerobic exercise on salivary cortisol, testosterone and immunoglobuline (A) in boys aged 15-16 years. Eur. J. Appl. Physiol. 107(4), 455-461 (2009)

37. Thomas NE, Leyshon A, Hughes MG, Jasper MA, Davies B, Graham MR, Bulloch JM, Baker JS: Concentration of salivary cortisol, testosterone and immunoglobuline (A) after supra-maximal exercise in female adolescents. J. Sports Sci. 16, 1-8 (2010)

38. Volek SJ, Rawson ES: Scientific basis and practical aspects of creatine supplementation for athletes. Nutr. 20, 609-614 (2004)

39. Walker JB: Creatine: biosynthesis, regulation and function. Adv. Enzymol. Relat. Areas Mol. Med. 50, 177-242 (1979)

40. Ziemba A: The role of creatine on forming exercise capacity and fatigue, and its use as a nutritional supplement in sports (Rola kreatyny w kształtowaniu zdolności wysiłkowej i zmęczenia oraz jej zastosowanie jako suplementu żywieniowego w sporcie). Med. Sport. 7(2), 117-124 (2003) 